\title{
Nilai Pendidikan Karakter pada Wangsalan Sindhenan Karya Nyi Bei Mardusari
}

\author{
Mambaul Khasanah', Suyanto $^{2}$, Sudiyanto ${ }^{3}$ \\ Program Studi S2 Pendidikan Seni, Pascasarjana Universitas Sebelas Maret Surakarta \\ Imambaul85@gmail.com
}

Wangsalan sindhenan merupakan salah satu bentuk karya sastra Jawa yang memiliki kandungan nilai- nilai luhur. Terdapat teka- teki dalam teks wangsalan yang membutuhkan sebuah metode untuk mengungkapkannya. Penelitian ini bertujuan untuk mengungkap dan menjelaskan teka teki dan nilai pendidikan karakter yang terkandung dalam wangsalan sindhenan serat Kidung Kandhasanyata Nyi Bei Mardusari. Penelitian ini merupakan jenis penelitian kualitatif dengan menggunakan metode pendekatan semiotik. Sumber data penelitian ini adalah teks wangsalan sindhenan dalam serat Kidung Kandhasanyata karya Nyi Bei Mardusari. Teknik pengumpulan data dilakukan dengan pembacaan dan pencatatan terhadap data yang diperoleh dari data pustaka dan wawancara. Analisis data menggunakan teknik pembacaan heuristik dan pembacaan hermeneutik dengan tahapan: (1) menterjemahkan teks wangsalan, (2) mengungkapkan teka- teki dan makna wangsalan, dan (3) menginterpretasi makna wangsalan secara filosofis. Hasil penelitian ini berupa nilai- nilai pendidikan karakter yang terkandung dalam wangsalan sindhenan karya Nyi Bei Madusari. Nilai- nilai pendidikan tersebut diantaranya nilai keimanan dan ketaqwaan, kesabaran, kemuliaan dan pengendalian diri. Nilai- nilai tersebut dapat digunakan sebagai media untuk menanamkan pendidikan karakter yaitu dengan memahami dan menginterpretasi makna yang terkandung di dalam wangsalan sehingga mampu menggerakkan rasa dan naluri pembaca untuk menjadi manusia yang lebih baik.

Kata kunci : wangsalan sindhenan, nilai pendidikan karakter.

\section{The Value of Character Education in Wangsalan Sindhenan by Nyi Bei Mardusari}

Wangsalan sindhenan is one form of Javanese literature that has a noble value. There are puzzles in wangsalan sindhenan texts that require a method to express them. This study aims to reveal and explain the puzzles and values of character education contained in Wangsalan Sindhenan Kidung Kandhasanyata Nyi Bei Mardusari fiber. This research is a type of qualitative research using the semiotic approach. The data source of this research is the Wangsalan text in Kidung Kandhasanyata fiber by Nyi Bei Mardusari. Data collection techniques are carried out by reading and recording data obtained from library data and interviews. Data analysis used heuristic reading techniques and hermeneutic reading with stages: (1) translating wangsalan text, (2) expressing puzzles and wangsalan meanings, and (3) interpreting wangsalan meaning philosophically. The results of this study are in the form of character education values contained in Wangsalan Sindhenan by Nyi Bei Madusari. These educational values include the value of faith and devotion, patience, glory and self-control. These values can be used as a medium to instill character education, namely by understanding and interpreting the meaning contained in the city so as to be able to move the sense and instinct of the reader to become a better human being.

Keywords : wangsalan sindhenan, value, character education.

Proses Review : 1 - 18 April 2019, Dinyatakan Lolos: 22 April 2019 


\section{PENDAHULUAN}

Salah satu tujuan utama bangsa Indonesia adalah memajukan sistem pendidikan guna membentuk sumber daya manusia yang lebih baik. Pendidikan menurut Nursyid Sumaatmadja (2002:40) diartikan sebagai proses perubahan perilaku, secara alamiah berjalan spontan. Pendidikan adalah pengaruh lingkungan atas individu untuk menghasilkan perubahan yang tepat didalam kebiasaan tingkah lakunya, pikiranya dan perasaannya (Thomson, 1977:2). Berdasarkan pernyataan tersebut dapat disimpulkan bahwa pendidikan adalah suatu proses penting yang bertujuan merubah pola pikir manusia sehingga berdampak pada perubahan sikap atau perilaku untuk menjadi manusia yang lebih baik.

Pendidikan di seluruh dunia kini sedang mengkaji perlunya dibangkitkan kembali pendidikan moral atau pendidikan budi pekerti yang sekarang lebih dikenal dengan sebutan pendidikan karakter (Solichin Dkk, 2011:129). Pentingnya pelaksanaan pendidikan karakter ini didasarkan atas pertimbangan beberapa faktor diantaranya: (1) semakin melemahnya hubungan dalam lingkup keluarga. Hal ini banyak dialami oleh keluarga saat ini. Banyaknya kesibukan dan permasalahan yang terjadi pada orang tua , sering menjadikannya lupa bahwa peran penting orang tua yaitu memberikan arahan dan pendidikan karakter kepada anaknya, (2) kondisi lingkungan generasi muda saat ini begitu memprihatinkan. Banyaknya tawuran antar pelajar, penggunaan obat- obatan terlarang, pencurian, pembunuhan, pelecehan seksual menjadikan pendidikan karakter dirasa penting untuk semakin ditingkatkan.

Lickona dalam (Mursidin, 2011:14) mengungkapkan bahwa sekurang- kurangnya terdapat 10 tanda kehancuran suatu bangsa, yakni: (1) meningkatnya kekerasan di kalangan remaja/ pelajar, (2) penggunaan bahasa dan kata- kata yang buruk, (3) pengaruh group yang kuat dalam tindakan kekerasan, (4) meningkatnya perilaku merusak diri seperti penggunaan narkoba, alkohol, seks bebas, dan lain- lain, (5) semakin kaburnya pedoman moral baik dan buruk, (6) menurunnya etos kerja, (7) semakin rendahnya rasa hormat kepada orang tua dan guru, (8) rendahnya rasa tanggung jawab individu dan warga negara, (9) membudayanya perilaku tidak jujur, dan (10) adanya rasa saling curiga dan kebencian di antara sesama.

Pendidikan karakter dapat dilakukan melalui berbagai cara, salah satunya yakni melalui memperdalam pemahaman tentang seni dan budaya bangsa yaitu karya sastra. Tidak banyak lagi masyarakat yang menghargai nilai- nilai luhur peninggalan para pendahulu, baik nilai ideologi, nilai sejarah, nilai moral, maupun nilai- nilai kehidupan lainnya (Solichin Dkk, 2011:129). Sampai saat ini kesadaran masyarakat tentang pentingnya memahami dan mempelajari nilai dalam karya sastra masih kurang. Karya sastra banyak mengandung nilai- nilai yang bermanfaat bagi masyarakat pembaca. Abrams (1979:14) menyatakan bahwa karya sastra itu bertujuan untuk mendidik moral dan menggerakan orang agar menjadi baik. Adapun nilai dalam karya sastra menurut Asia Padmopuspito (1990:4) berupa ajaran, pesan, dan nilai-nilai kehidupan yang dapat digunakan sebagai bahan piwulang (ajaran). Atar Semi (1994:20) mengungkapkan bahwa nilai dalam karya sastra diharapkan dapat memberi solusi atau sebagian masalah dalam kehidupan masyarakat.

Salah satu wujud karya sastra yang perlu diapresiasi lebih lanjut yaitu wangsalan sindhenan. Wangsalan adalah teks atau syair yang digunakan seorang sindhen dalam sajian gending Jawa. Menurut Padmoesoekotjo "Wangsalan yaiku unen- unen saemper cangkriman, nanging batange lumrahe dikandhakake pisan ana ing gatra tjandake utawa ing ukara candake."( Padmoesoekotjo, 1956:5). Artinya bahwa wangsalan adalah kata-kata yang menyerupai teka-teki disertai dengan jawaban tersamar tetapi jawaban dikatakan dalam kata atau kalimat selanjutnya (Padmoesoekotjo 1956:5).

Penelitian ini mengungkap nilai pendidikan karakter pada wangsalan sindhenan karya Nyi Bei Mardusari. Pemilihan objek penelitian ini berdasarkan pada pertimbangan kandungan nilai pendidikan yang terdapat di dalamnya. Nilai pendidikan tersebut diantaranya yaitu hubungan antara manusia dengan Tuhan, manusia dengan sesama manusia, dan manusia dengan dirinya sendiri. Untuk mengungkap nilai yang terkandung dalam teks wangsalan, digunakan teori semiotik Michael Riffaterre. Sesuai dengan teori Riffaterre, langkah semiotik pertama yaitu melakukan penelitian teks melalui tahap pembacaan heuristik. Pembacaan heuristik adalah pembacaan yang didasarkan pada konvensi bahasa yang bersifat mimetic (tiruan alam) dan membangun serangkaian arti yang heterogen, berserak- serakan atau ungramatikalitas (Suroso \& Santosa, 2009:70). Pembacaan heuristik juga dapat diartikan dengan pemaknaan teks secara lugas atau apa adanya. Langkah selanjutnya yaitu melakukan pembacaan hermeneutika. Pembacaan hermeneutika ini mendasarkan pada konvensi sastra dan budaya. Artinya, dari pemahaman makna kebahasaan yang masih beraneka ragam dan menampakkan adanya keterpecahan (semiotika tataran pertama), pembaca puisi harus bergerak lebih jauh untuk memperoleh kesatuan makna puisi secara menyeluruh (semiotika tataran kedua) (Suroso \& Santosa, 2009:69).

\section{METODE PENELITIAN}

Penelitian ini menggunakan metode kualitatif. Penelitian ini mendiskripsikan nilai- nilai serta memberikan pemaknaan terhadap simbol- simbol yang terkandung dalam wangsalan sidhenan. Teknik pengumpulan data dilakukan dengan melakukan observasi pustaka yaitu buku- buku yang mendukung dan relevan dengan objek penelitian seperti Bausastra Jawa dan sumber- sumber tentang wangsalan 
sindhenan. Selain observasi pustaka peneliti juga melakukan tahap wawancara dengan melibatkan narasumber ahli yaitu dalam bidang sastra jawa khususnya ilmu sindhenan. Selama proses pengumpulan data peneliti menggunakan teknik pembacaan dan teknik pencatatan data.

Tahapan selanjutnya yaitu tahap analisis data. Kaelan (2005:68) mengungkapkan bahwa analisis data merupakan proses mengatur urutan data, kemudian mengorganisasikannya ke suatu pola, kategori dan satuan uraian dasar. Tahapan analisis data dalam penelitian ini yaitu: Pertama, memahami makna dan simbol- simbol dalam teks wangsalan sindhenan dengan menggunakan metode pemahaman atau verstehen. Tahap ini merupakan langkah awal untuk menangkap makna dan simbol- simbol dalam teks wangsalan sindhenan. Kedua, peneliti melakukan interpretasi terhadap teks wangsalan sindhenan. Metode ini merupakan metode lanjutan dari tahap pemahaman atau verstehen. Dalam tahap interpretasi ini peneliti mengungkapkan, menjelaskan dan menterjemahkan teks wangsalan sindhenan agar lebih komunikatif dan mudah untuk dipahami. Ketiga, yaitu tahap penafsiran. Sesuai dengan teori Riffaterre tentang semiotik maka penafsiran makna disini dilakukan dalam dua tahap yaitu metode heuristik dan hermeutika. Metode heuristik yaitu pemaknaan yang dilakukan secara apa adanya. Untuk mendapatkan makna teks secara keseluruhan maka dilakukan metode hermeneutika yaitu pemahaman makna lebih mendalam. Tujuan Hermeneutika adalah untuk mencari dan menemukan makna yang terkandung dalam objek penelitian yang berupa fenomena kehidupan manusia, melalui pemahaman dan interpretasi (Irmayanti, 2002:70). Menurut Schleiermacher (1977:22) mengungkapkan bahwa prinsip kerja hermeneutika adalah untuk menangkap objective geist yang terkandung dalam objek penelitian. Objevtive geist dapat pula diartikan makna yang terdalam, hakikat nilai yang terkandung dalam objek penelitian. Setelah melakukan tahap ini maka peneliti akan dapat mengungkap nilai pendidikan yang terdapat pada teks wangsalan sindhenan dan makna wangsalan secara utuh atau menyeluruh.

\section{ANALISIS DAN INTEPRETASI DATA}

Wangsalan merupakan salah satu karya sastra Jawa yang digunakan pesindhen sebagai syair dalam menyajikan sebuah gending. Wangsalan merupakan karya sastra yang begitu rumit untuk dipahami. Hal ini dikarenakan dalam wangsalan menggunakan jenis bahasa jawa kuna atau kawi yang makna nya sengaja tidak diuraikan secara langsung. Kata wangsalan menurut Subroto (2000:16) dibentuk dari kata wangsal yang berarti jawab atau menjawab. Dijelaskan pula bahwa wangsalan adalah salah satu bentuk puisi (tembang) Jawa yang didalamnya terdapat semacam teka-teki dan sekaligus jawabannya namun jawaban tersebut tidak diberikan secara jelas atau tersurat tetapi secara samar-samar atau tersirat. Wijoyanto (2014:14) menjelaskan bahwa struktur wangsalan mirip dengan parikan atau pantun. Artinya wangsalan terdiri atas sampiran dan isi. Bedanya dengan pantun, sampiran dalam wangsalan berupa cangkriman atau teka teki yang harus ditemukan batangannya.

Wangsalan terdiri dari dua baris, baris pertama yaitu merupakan baris pertanyaan atau disebut dengan baris karep. Baris kedua merupakan baris jawaban atau disebut juga dengan batangan. Menurut Kadarisman (2010:131) batangan pada wangsalan berfungsi sebagai kata kunci untuk menemukan maksud yang muncul secara parsial pada baris isi. Karep wangsalan akan berhasil ditemukan bila mempunyai hubungan parsial dengan batangan. Hubungan parsial berarti antara batangan dan karep hanya bertalian bunyi secara tersamar. Artinya pertalian tersebut hanya perulangan bunyi satu suku kata atau lebih namun tidak sama persis.

Setelah teka- teki dari wangsalan dapat ditemukan, selanjutnya yaitu mencari makna wangsalan secara keseluruhan sehingga dapat mengungkap pesan dan kandungan isinya. Berikut ini adalah beberapa wangsalan yang akan diungkapkan teka- teki dan maknanya:

\section{Sindhu raga, raga kang datanpa daya; Dipun- enget, ywa supe bekti ing Suksma.}

Kata Sindhu raga menurut Prawiroatmodjo (1996:691) dalam Kamus Bausastra Jawa, sindhu adalah air, sedangkan raga adalah tubuh. Yaitu air yang keluar dari tubuh manusia adalah keringat, dalam bahasa Jawa disebut dengan keringet. Maka enget adalah jawaban dari teka teki tersebut karena terdapat kata "nget". Raga kang datanpa daya artinya raga yang sudah tidak berdaya. Orang Jawa menyebutnya dengan istilah lempe-lempe. Jawaban dari pertanyaan tersebut adalah kata supe karena mengandung kata "pe". Makna wangsalan diatas terdapat dalam baris isi yakni Dipun- enget, ywa supe bekti ing Suksma yang artinya ingatlah, jangan lupa untuk berbakti kepada Tuhan. Secara aksiologis untaian kata- kata itu mengandung nilainilai pendidikan bahwa manusia harus selalu percaya dan taqwa kepada Tuhan Yang Maha Esa. Sikap berbakti kepada Tuhan dapat dicerminkan melalui rajin beribadah, senantiasa menjalankan perintahNya dan menjauhi laranganNya.

\section{Jalak pita, pita konyoh 'sring kinarya; Sagung coba, tinampan sareh ing karsa.}

Jalak pita adalah burung berwarna kuning. Burung yang dimaksud disini adalah burung Menco. Oleh karena itu pada baris isi atau baris jawaban tertulis kata coba. Kemudian kalimat pita konyoh 'sring kinarya, konyoh berarti boreh (Prawiroatmodjo, 1996:263). Boreh adalah sejenis bedak atau lulur yang dicampur dengan kunyit dan cendana. Pada baris isi, kalimat Sagung coba, tinampan sareh ing karsa artinya adalah segala cobaan diterima dengan sabar. Pesan 
yang dapat kita renungkan adalah selalu berusaha menjadi manusia yang sabar dengan menahan segala amarah dan menerima keadaan dengan iklhas. Menurut Ibnu Qayyim dalam (Hidayatullah, 2010:42) mengemukakan adanya empat sendi karakter baik. salah satu sendi tersebut adalah karakter sabar, yakni yang mendorongnya menguasai diri, menahan amarah, tidak mengganggu orang lain, lemah lembut, tidak gegabah dan tidak tergesa- gesa.

\section{Wastra seta, jarwa arane aldaka; Aja meri, mring wong kang sinung nugraha.}

Wastra seta adalah kain putih. Banyak orang menyebut kain putih dengan sebutan mori. Oleh karena itu jawabannya terdapat pada kata meri. Kata "ri" pada meri mewakili mori. Selanjutnya Jarwa arane aldaka adalah gunung. Aldaka merupakan bahasa Sansekerta yang berarti nama lain dari gunung (Prawiroatmodjo, 1996:6). Sehingga jawabannya terdapat pada baris isi yaitu kata sinung karena mengandung kata 'nung'. Makna keseluruhan wangsalan ini yaitu "Aja meri, mring wong kang sinung nugraha". Artinya janganlah iri pada orang yang mendapatkan anugrah. Jika kita perhatikan kondisi masyarakat sekarang ini, sifat iri merupakan salah satu penyebab terjadinya permusuhan dan kesenjangan- kesenjangan lainnya. Contohnya: tidak senang ketika orang lain mendapatkan rejeki/penghargaan/anugrah. Rasa tidak senang tersebut kemudian berubah menjadi dendam yang akhirnya timbul niat- niat jahat untuk mengambil hak orang lain. Iri merupakan salah satu sendi dari karakter yang buruk.

\section{Cengkir wungu, tapane Sang Dananjaya; Aja uwal, denira amatiraga.}

Cengkir wungu adalah buah kelapa yang masih kecil. Orang Jawa biasa menyebutnya dengan nama siwalan. Maka jawaban dari pertanyaan tersebut adalah $u$ wal. Kata "wal" dalam kata uwal sudah mewakili jawaban yang dimaksud yakni siwalan. Kemudian maksud dari tapane Sang Dananjaya adalah menceritakan Dananjaya yaitu nama lain dari Raden Arjuna saat bertapa. Saat bertapa Raden Arjuna berganti nama menjadi Begawan Mintaraga. Minta berarti mengendalikan/menyingkirkan dan raga berarti hawa nafsu, jadi Begawan yang senantiasa mengendalikan hawa nafsu. Kata mintaraga tersirat dalam baris jawaban yakni pada kata amatiraga yang memiliki arti sama yaitu mengendalikan hawa nafsu. Jadi makna wangsalan ini "Aja uwal, denira amatiraga" yaitu jangan lepas atau jangan berhenti untuk senantiasa mengendalikan hawa nafsu. Pengendalian hawa nafsu merupakan titik terpenting dalam kehidupan. Dengan selalu mengendalikan hawa nafsu kita sebagai manusia lebih mengerti bagaimana bersikap yang baik kepada Tuhannya, bagaimana bersikap baik kepada orang lain dan bersikap baik kepada diri sendiri.

\section{Aran wastra, wastra laranganing nata; \\ Dipun- sirik, agawe rusak-ing bala.}

Aran berarti sebutan, penamaan. Sedangkan wastra memiliki arti kain, sandhangan (Pakaian). Salah satu sebutan kain yang dikenal oleh masyarakat Jawa yaitu jarik. Jawaban atas teka teki atau pertanyaan tersebut terdapat pada kata sirik, yang diwakili dengan "rik". Teka- teki selanjutnya yaitu "wastra laranganing nata" artinya kain (jarik) yang dilarang oleh raja. Masyarakat Jawa banyak yang mengerti dan menuruti larangan tersebut terutama masyarakat dalam lingkungan keraton. Terdapat aturan bahwa tidak ada yang diperbolehkan untuk memakai jarik yang bermotif parang. Motif parang sendiri terdiri dari beberapa macam diantaranya: . Maka jawaban atas teka- teki diatas adalah kata rusak, maksudnya adalah jenis motif parang rusak.

Selanjutnya arti keseluruhan dari baris isi wangsalan diatas adalah "Dipun-sirik agawe rusak-ing bala" artinya hindarilah untuk merusak sebuah pertemanan. Kalimat isi tersebut mengandung makna yang dalam, bahwa sebagai manusia sebaiknya selalu menjaga hubungan pertemanan agar silaturahmi senantiasa terjalin dengan baik. Perintah tersebut juga terdapat dalam kitab- kitab suci yaitu akan mendapatkan dosa besar apabila manusia dengan sengaja merusak tali pertemanan yang berdampak buruk terhadap silaturahmi antar sesama.

\section{Peken alit, wreksa 'rum kang den la- ela; Aja ndlarung,kendhonana tyas kang harda.}

Kata 'peken' dalam bahasa indonesia berarti pasar. Sedangkan 'alit' artinya yaitu kecil. Sebutan lain untuk pasar yang kecil yaitu warung. Oleh karena itu pada baris kedua disebutkan kata 'ndlarung'. Kata tersebut merupakan jawaban dari peken alit atau pasar kecil yaitu warung. Kata warung sudah diwakilkan dalam kata rung pada 'ndlarung'. Selanjutnya pada baris pertanyaan tertulis wreksa 'rum kang den la- ela. 'Wreksa' artinya kayu, kata 'rum maksudnya yaitu arum dalam bahasa indonesia harum. Den ela- ela artinya yaitu diistimewakan atau di cari- cari. Jadi maksud kalimat pertanyaannya yaitu kayu harum yang dicari- cari atau diistimewakan banyak orang. Jawaban dari pertanyaan tersebut maksudnya yaitu kayu cendhana. Maka 'kendhonana' merupakan kunci jawaban dari pertanyaan atau teka- teki tersebut.

Makna keseluruhan wangsalan terdapat pada baris isi yaitu ' aja ndlarung, kendhonana tyas kang harda' artinya yaitu jangan berlebihan, kendalikan keinginan atau niatan yang berlebihan. Maksud dari isi wangsalan ini yaitu mengajarkan kepada manusia bahwa tidak dianjurkan mempunyai sifat dan sikap yang berlebihan. Manusia jika mempunyai niat terkadang sering diluar batas sehingga untuk mendapatkan keinginan tersebut manusia tidak sadar telah melakukan hal- hal diluar batas. Sifat seperti itu sering disebut dengan ambisi. Manusia memang dianjurkan memiliki ambisi untuk menjadi lebih baik, akan tetapi ambisi akan menjadi sesuatu yang membahayakan apabila 
tidak dikendalikan dengan cara yang baik.

\section{SIMPULAN}

Berdasarkan hasil penelitian, dapat disimpulkan bahwa karya sastra wangsalan sindhenan mengandung nilai-nilai dan ajaran yang bermanfaat untuk para pembaca. Wangsalan sindhenan dalam serat Kidung Kandhasanyata karya Nyi Bei Mardusari banyak mengandung nilai- nilai pendidikan karakter yaitu tentang nilai keimanan kepada Tuhan Yang Maha Esa, kesabaran dalam menghadapi cobaan, menghindari sifat iri dan dengki, menjaga tali persaudaraan dan pertemanan, senantiasa mengendalikan diri, agar menjadi pribadi yang positif bagi Tuhan, sesama manusia dan dirinya sendiri.

Peran pendidikan melalui pemahaman karya sastra khususnya wangsalan sindhenan menjadi penting dalam meningkatkan pendidikan karakter manusia. Melalui pemahaman nilai- nilai yang terkandung di dalam teks wangsalan sindhenan ini diharapkan dapat bermanfaat dan memberikan dampak positif bagi para pembaca, sehingga mampu menjadi manusia yang lebih baik dan peduli terhadap warisan budaya bangsa.

\section{SARAN}

Penelitian tentang karya sastra wangsalan sindhenan merupakan penelitian yang langka atau belum banyak dilakukan. Harapan penulis dengan hasil penelitian ini dapat menggerakkan minat khususnya remaja atau peserta didik untuk bisa mempelajari, memahami dan mempraktikkan nilai yang terkandung dalam wangsalan sindhenan. Penelitian ini juga dapat dijadikan sebagai bahan acuan bagi para pendidik untuk lebih luas dalam mencari bahan ajar khususnya materi tembang jawa. Melalui pengetahuan mengenai wangsalan sindhenan, akan menambah pengetahuan siswa atau peserta didik bahwa karya sastra jawa khususnya tembang sangat beragam. Wangsalan sindhenan adalah salah satunya yang penting untuk dipelajari lebih lanjut sehingga pemahaman, kecintaan dan penghayatan generasi penerus terhadap nilai dari peninggalan karya sastra terdahulu semakin meningkat.

\section{DAFTAR RUJUKAN}

Abrams, M. H. (1979). The Mirror and The Lamp. Oxford: Oxford University Press.

Hidayatullah, M. Furqon. (2010). Pendidikan Karakter: Membangun Peradaban Bangsa. Surakarta: Yuma Pustaka.

Irmayanti, M. Budianto. (2002). Realitas dan Objektivitas: Refleksi Kritis Atas Cara Kerja Ilmiah. Jakarta: Wedya Sastra.
Kadarisman, A. Effendi. (2010). Mengurai Bahasa Menyibak Budaya. Bunga Rampai Linguistik, Puitika dan Pengajaran Bahasa. Malang: UIN- Maliki Press.

Kaelan. (2005). Metode Penelitian Kualitatif Bidang Filsafat; Paradigma Bagi Pengembangan Penelitian Interdisipliner Bidang Filsafat, Budaya, Sosial, Semiotika, Sastra, Hukum dan Seni. Yogyakarta: Penerbit Paradigma.

Mursidin, (2011). Moral, Sumber Pendidikan. Bogor: Ghalia Indonesia.

Padmopuspita, Asia. (1990). Citra Wanita dalam Sastra Dalam Cakrawala Pendidikan. Yogyakarta: Lembaga Pengabdian Masyarakat.

Padmosoekotjo, S. (1956). Ngengrengan KasusastranJawa II. Yogyakarta: Hien Hoo Sing.

Prawiroatmodjo, S. (1996). Bausastra Jawa-Indonesia. Jakarta: PT Karya Unipress.

Schleiermacher. F.D.E. (1977). Hermeneutics: The Handwritten Manuscripts, (ed.) Heinz Kimmerle. Terj: James Duke \& Jack Forstman. Montana: Scholars Perss.

Semi, M. Atar. (1994). Metode Penelitian Sastra. Bandung: Angkasa.

Solichin, Suyanto, Setiawan A., Zuriah N., Nurrochsyam M Wildha. (2011). Pendidikan Budi Pekerti dalam Pertunjukan Wayang. Jakarta: Yayasan Sena Wangi.

Subroto, Edi. (2000). Kajian Wangsalan dalam Bahasa Jawa. Jakarta: Pusat Bahasa Departemen Pendidikan Nasional

Sumaatmadja, Nursyid. (2002). Pendidikan Pemanusiaan Manusia Manusiawi. Alfabeta: Bandung.

Suroso., Santosa, Puji. (2009). Estetika: Sastra, Sastrawan \& Negara. Yogyakarta: Pararaton Publishing

Thomson, Godfrey. (1977). Dasar Konsep Pendidikan Moral. Jakarta: Alfabeta.

Wijoyanto, Danang. (2014). Ngripta lan Negesi Wangsalan. Dalam Majalah: Jayabaya No. 4 Minggu IV September 2014. Surabaya: Temprina Media Grafika. 